Article

\title{
Knowledge and Attitudes Towards Nutrigenetics: Findings from the 2019 Unified Forces Preventive Nutrition Conference (UFPN)
}

\author{
Vered Kaufman-Shriqui ${ }^{\circ}$, Hagit Salem, Mona Boaz $₫$ and Ruth Birk *(i) \\ Department of Nutritional Sciences, School of Health Sciences, Ariel University, Ariel 40700, Israel \\ * Correspondence: ruthb@ariel.ac.il; Tel.: +972-3-976-5704; Fax: +972-3-542-3553
}

Received: 18 December 2019; Accepted: 24 January 2020; Published: 27 January 2020

\begin{abstract}
Background: Nutrigenetics indicates that individual genetic variability results in altered health outcomes necessitating personalized nutrition adaptation. Registered dietitians are recognized as the clinical nutrition experts, but their knowledge and attitudes regarding nutrigenetics has not been delineated. Methods: This cross sectional online survey was conducted in a convenience sample of 169 national nutrition conference attendees. The survey queried demographics, knowledge, and attitudes towards nutrigenetics and information on training in nutrigenetics. Results: The majority of participants were registered dietitians and female, $45 \%$ of whom held advanced degrees. Personalized nutrition was perceived by $93.5 \%$ of participants as highly important or important; however, $94 \%$ of respondents indicated they are not sufficiently knowledgeable in personalized nutrition and only $9.5 \%$ had received training in nutrigenetics. The mean nutrigenetics knowledge score was $6.89 \pm 1.67$ (out of a possible 12). A multivariate regression model of knowledge score identified education as the only independent predictor of this outcome. Conclusion: Personalized nutrition is a rapidly developing field that incorporates genetic data into clinical practice. Dietitians recognize the importance of advanced studies to acquire knowledge in nutrigenetics. Only by acquiring the necessary knowledge can dietitians accurately translate this nutrigenetics into clinical practice.
\end{abstract}

Keywords: dietitian; nutrigenomics; nutrigenetics; nutrition survey; education

\section{Introduction}

The post-genomic era is characterized by the rapid incorporation of genetic information into the fields of medicine and nutrition. The Human Genome Project, the 1000 Genomic Project, Genomics England and others have significantly advanced scientific knowledge regarding individual (personal) risk, pathophysiology, and treatment of common diseases [1-3]. In parallel, genetic information is increasingly introduced into the clinical setting, as well as to the scientific and clinical literature. Genetic tests are becoming an essential instrument in the toolbox of clinicians in medical and para-medical professions [4]. Additionally, genetic tests are marketed to the public through Direct-To-Customer companies, resulting in increasing consumer demand for interpretation and advice based on personal genetic information. Unfortunately, many clinical professionals, including registered dieticians, lack the knowledge and skills required to effectively deliver genetic services [5-9]. The challenges regarding the practical application of nutritional genomics were well demonstrated by a cross sectional online study by Collins et al., in which poor knowledge, involvement, and confidence in genetics and nutritional genomics was observed in 1844 dietitians from the US, Australia, and UK [10]. In light of this, the American Academy of Nutrition and Dietetics published a position paper [11] stating that: "registered dietitian nutritionists need basic competency in genetics as a foundation for understanding nutritional 
genomics; proficiency requires advanced knowledge and skills." Due to the complexity of genetic information and the interaction with environmental factors, including nutrition, the position paper further specifies that: "applying nutritional genomics in clinical practice through the use of genetic testing requires that registered dietitian nutritionists understand, interpret, and communicate complex test results in which the actual risk of developing a disease may not be known." Currently, although highly relevant to their profession, traditional dietitians' curricula and/or training do not include extensive and wide training in advanced human genetics, including facets such as omics technology, interpretation of genetic variation information, as well as legal, ethical, and social aspects of genetic information, among others. Furthermore, in several countries, including Israel, dietitians are not legally entitled to counsel, preform, or treat patients using genetic information.

Nutrigenetics or personalized nutrition is based on individual genetic variability that results in altered health outcome, and ultimately involves nutrition adjustment. As individual genetic information is stable from birth throughout life, and as its personal delineation has become feasible and relatively inexpensive, the incorporation of genetic information to routine medicine and nutrition/dietetics is becoming essential. For example, lactose intolerance, a common clinical phenotype worldwide (ranging from $0-90 \%$ of the population in different ethnicities), is caused by low to absent intestinal lactase activity, which results in a variety of symptoms, such as abdominal pain, flatulence, bloating and diarrhea, following lactose exposure. Consequently, many exclude milk and milk products (rich in lactose) from the diet, with consequent lack of calcium in the body and ultimately elevated risk of osteopenia and osteoporosis later in life [12,13]. Genetic single nucleotide polymorphisms (SNPs) (C>T-13910 and G>A-22018), located upstream to the lactase gene, have been strongly associated with adult lactose intolerance / persistence in several populations [14-16]. Due to the complexity and sensitivity of common biochemical and histological current methods of diagnosis, incorporating genetic screening for these common variations can significantly improve early diagnosis of lactase intolerance, enabling nutritional strategies to alleviate gastrointestinal symptoms in parallel to providing RDA calcium intake [17]. Despite these advancements, translation of nutrigenetics to the clinical setting is challenging and gradual and should be incorporated in light of restricted and evidence-based knowledge [18]. The potential impact of nutrigenetics has led to initiatives focused on changing consumer nutrition behavior, such as the EU-funded Food4Me project, which employs internet-delivered personalized nutrition (PN) [19-22].

Little is known regarding dietitians' attitudes towards and knowledge of genetics and nutrigenomics. Existing data suggest that knowledge of nutrigenomics and nutrigenetics among dietitians is insufficient and varies across countries [10]. This study aims to assess the level of knowledge in genetics among health care professionals participating in a national Israeli nutrition conference and to estimate the associations between knowledge, sociodemographic characteristics, attitudes, and training in nutrigenomics.

\section{Materials and Methods}

\subsection{Overall Study Design and Plan}

This cross sectional survey was conducted in a convenience sample of nutrition conference attendees. The survey queried demographics, knowledge, and attitudes towards nutrigenetics and information on professionals' training in nutrigenetics. Investigators sent an online survey to all dietitians and other health professionals registered to participate in a large, national nutrition conference.

\subsection{Informed Consent}

The present study was approved by the Institutional Ethics Committee (Helsinki Committee), Ariel University (AU-HEA-RB-20190523). Response to the survey indicated informed consent as stated on the first screen of the online study. 


\subsection{Study Population}

All individuals who registered to attend the 17th Annual Preventive Nutrition-Combined Forces Israel Nutrition Week Conference received a link to an online survey administered via Google Surveys. Conference organizers indicated that approximately 3000 individuals registered for the event. As this conference is the largest annual nutrition conference in Israel, attended by dietitians, researchers, physicians, nurses, and other health professionals, the investigators selected this venue as a framework in which to query professionals in these fields. Conference organizers permitted researchers to utilize the registration lists as a target population.

\subsection{Inclusion Criteria}

All individuals who were registered for the conference and responded to our email were sent a link to the online survey. The ability to respond to the survey, which was conducted in Hebrew, de facto included only individuals who are literate in Hebrew.

\subsection{Facilitating Participation}

To encourage participation in the survey, respondents were entered into a lottery for professionally meaningful prizes, including a digital scale and professional literature.

\subsection{Survey Development}

The survey included 24 questions surveying knowledge (12 multiple choice questions); training and attitudes in personalized nutrition (six questions, three on each topic); (File S1) and demographics (six questions). Demographic characteristics included personal information (age, sex, highest academic degree) and professional experience (profession, years in profession, employment setting). Demographic questions were mostly multiple choice (e.g., list of professions and employment settings), while report of years in profession and age were open questions.

Knowledge questions on genetics and nutrigenetics were developed using a previously validated survey instrument, which was administered to dietitians in the US, UK, and Australia [10]. The questionnaire was translated to Hebrew, and then translated back to English by a different translator to ensure content validity. Most of the original questions were retained in the Hebrew questionnaire, and additional questions were added to reflect the current university-level introductory genetics course syllabus, which is compulsory for students studying towards an undergraduate degree in Nutrition Sciences in Israel. Knowledge questions were only related to nutrigenetics (Nutrigenetics or personalized nutrition is based on individual genetic (DNA) variability that results in individual nutrition recommendations).

A screening question examined participant training in PN counselling (incorporating genetic information into clinical nutrition practice). Respondents who replied positively were asked to indicate the duration of the course and, separately, the frequency of full-text research articles in nutrigenetics they read annually. These questions were also multiple choice. Finally, using a scale of $0-4$, participants were asked to rate the importance of PN.

Once refined, face validity and online usability were determined through a pilot survey of 24 undergraduate nutrition students, and minor modifications were made based upon feedback. The survey was then graphically adapted for administration on mobile phones. Finally, five registered dietitians, providing expert validity, reviewed and approved the final version of the questionnaire.

\subsection{Data Analysis}

SPSS v. 25.0 (IBM Inc., PASW Inc., Chicago, IL, USA) was used for all statistical analyses. Distributions of continuous variables were approximately normally distributed as assessed using the Kolmogorov-Smirnov test; thus, these are described using the mean \pm standard deviation. Categorical variables such as the proportion of participants with a given response were described 
using frequency counts and expressed as $n(\%)$. Continuous variables were compared by profession using one-way analysis of variance (ANOVA). The associations between categorical variables were assessed using the chi- square test. The knowledge score was calculated as the sum of correct answers to the knowledge questions and ranged from 0-12. A multivariate regression model examined the association between sociodemographic characteristics of the participants and knowledge score (a score in the highest tertile vs. lower scores). All tests are two-sided and considered significant at $p<0.05$.

\section{Results}

Table 1 describes the survey participants. The majority of participants were registered dietitians and female. The areas of study for the highest degree of education included nutrition (53.8\%); public health (11.2\%); management (7.7\%); medical sciences (5.5\%); and epidemiology (2.4\%). Additionally, $18.9 \%$ of respondents indicated that their highest degree was in another (unspecified) field. More than $45 \%$ of survey participants held advanced degrees. PN was perceived by $74 \%$ of the sample as highly important within the field of nutrition; an additional 19.5\% rated the field as important. Most respondents (94\%) indicated they are not sufficiently knowledgeable in PN. Only 9.5\% received training in nutrigenetics Of these, $73.5 \%$ had participated in a one-day seminar and an additional $21.3 \%$ were trained in a basic (but not advanced) human genetics course during their academic studies. While $31.4 \%$ of the participants replied that they read journal articles in the field of PN annually, most (47.9\%) read less frequently than annually.

Table 2 presents the proportion of correct responses to the knowledge questions on genetics and nutrigenetics. The mean knowledge score was $6.89 \pm 1.67$, with no difference in the total score detected a cross health professions or workplace settings.

Only $10 \%$ of participants correctly identified the definition of nutrigenetics. Compared to other health professionals, a greater proportion of dietitians in comparison to other professionals correctly recognized the definition of "phenotype" (97.1\% vs. $88.1 \%$, respectively); additionally, a greater proportion identified a disease that is not multifactorial ( $83.3 \%$ vs. $62.7 \%$, respectively).

A multivariate regression model was developed to examine the characteristics of participants in the highest knowledge score tertile (nine points and higher). The model indicated that the only significant predictor was education. Individuals with a MSc degree or higher were 4.4 times more likely to receive a knowledge score of nine and above (Table 3).

Table 1. Characteristics of survey participants $(n=169)$.

\begin{tabular}{cc}
\hline Characteristic & Result \\
\hline Age (years) & $37.9 \pm 10.4$ \\
\hline Sex $n,(\%$ female $)$ & $159(94.1)$ \\
\hline Profession $n,(\%)$ & \\
\hline Dietitian & $102(60.4)$ \\
\hline Student/intern & $21(12.4)$ \\
\hline Food technologist & $20(11.8)$ \\
\hline Nurse & $4(2.4)$ \\
\hline Physician & $2(1.2)$ \\
\hline Other & $20(11.8)$ \\
\hline Highest level of education $n,(\%)$ & $77(45.6)$ \\
\hline BSc, BA & $74(43.8)$ \\
\hline MSc, MA, MPH, MBA & $9(5.3)$ \\
\hline PhD &
\end{tabular}


Table 1. Cont.

\begin{tabular}{cc}
\hline Characteristic & Result \\
\hline MD & $1(0.6)$ \\
\hline Undergraduate student & $8(4.7)$ \\
\hline Employment setting $n,(\%)$ & $14(8.3)$ \\
\hline Private clinic & $42(24.9)$ \\
\hline Hospital & $19(11.2)$ \\
\hline Health maintenance organization clinic & $5(3.0)$ \\
\hline Academia & $11(2.4)$ \\
\hline Private company conducting clinical \\
research & $21(12.4)$ \\
\hline Food industry & $2(1.2)$ \\
\hline Drug industry & $7(4.1)$ \\
\hline Unemployed & $47(27.8)$ \\
\hline Other & $10.7 \pm 10.5$ \\
\hline Work experience, years (mean \pm SD) &
\end{tabular}

Table 2. Professionals' attitudes, training, and knowledge of genetics and nutrigenetics $(n(\%))$.

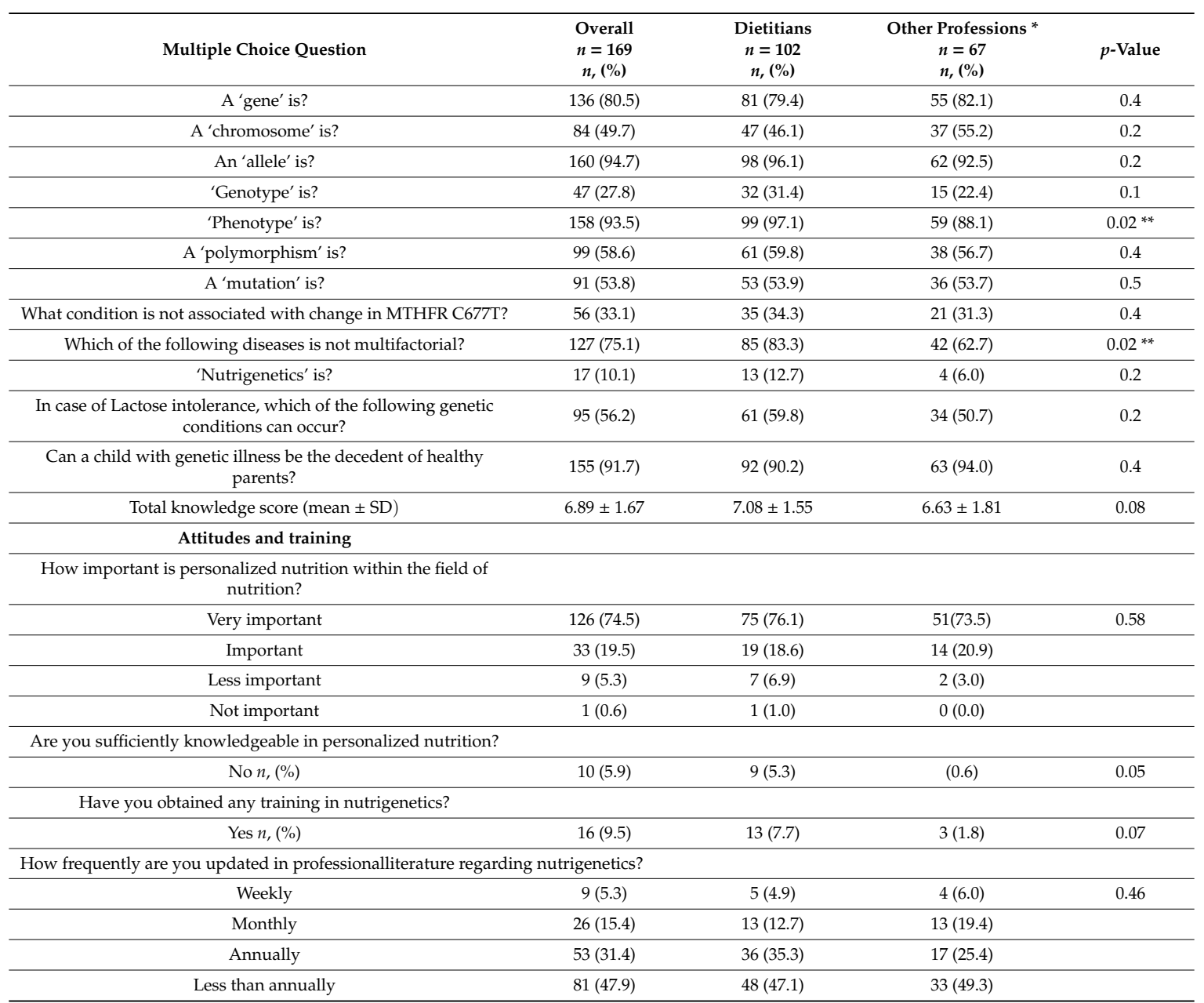

* Other health professions comprised $39.6 \%$ of the sample, of them: Students and interns (12.5\%), food technologist

$(11.9 \%)$, nurses $(1.9 \%)$, physicians $(1.2 \%)$, and others $(11.5 \%){ }^{* *} p<0.05$. 
Table 3. Factors associated with total knowledge score higher than nine points in multivariable logistic regression analysis.

\begin{tabular}{cccc}
\hline & Odds Ratios & $\mathbf{9 5 \%}$ CI & $p$ Value \\
\hline Age (years) & 1.01 & $0.97-1.06$ & 0.51 \\
\hline Sex (women vs. men) & 1.64 & $0.18-14.88$ & 0.66 \\
\hline Profession (dietitians vs. other) & 0.65 & $0.25-1.71$ & 0.38 \\
\hline Academic Degree (MSc and above vs. BSc and below) & 4.03 & $1.34-12.11$ & 0.013 \\
\hline Employment setting (clinical vs. other) & 1.29 & $0.48-3.46$ & 0.61 \\
\hline Constant & 0.03 & & 0.14 \\
\hline
\end{tabular}

\section{Discussion}

This study investigated the level of knowledge in nutrigenetics and attitudes towards nutrigenetics knowledge and counselling among health care professionals participating in the leading annual nutrition conference in Israel. We found that the overwhelming majority $(93.5 \%)$ of the participants perceived PN counselling as highly important within the field of nutrition; however, the mean knowledge survey score was $6.89 \pm 1.67$ out of 12 , with substantial variation across different genetic themes. Similar levels of knowledge were reported in previous studies, which showed that dietitians had insufficient knowledge in nutritional genomics and were not confident in their ability to clinically implement it [23]. These findings are also in line with the reports of Whelan et al. [24] and McCarthy et al. [25], showing an average genetic knowledge score of $41 \%$ among UK dietitians. The fact that the genetic score findings in our study do not differ significantly from those in other studies performed more than a decade ago, suggest that genetic education to improve dietitians' knowledge was not implemented. Furthermore, the fact that similar results regarding the level of dietitians' knowledge in genetics are shown across time and countries indicate that this challenge is universal.

In our study, the single predictor for higher knowledge score was education. No difference in the total score was detected across health professions or workplace settings.

Israeli registered dietitians scored similarly to their colleagues in the USA, UK, and Australia [10], though variations across questions were significant. For example, while $90.1 \%$ of professionals at the Collins et al. sample selected the correct definition of chromosome, only $46.1 \%$ of the registered dietitians in our sample replied correctly. Conversely, $92.5 \%$ of the registered dietitians in our sample identified the correct definition of allele compared to only $43.2 \%$ of the Collins et al. sample. These differences may reflect differences in university curricula across countries.

The need to incorporate advanced courses in nutrigenetics in the already packed health sciences and particularly dietetics curricula has been both identified and challenged [26]. The challenge appears to reflect the multidisciplinary complexity of nutrigenetics, encompassing many fields including genetics, nutrition, statistics, ethics, and law. The challenge of incorporating advanced genetics education has been identified across many health disciplines, including cardiology [27], primary care [28], and occupational therapy [29]. Advanced genetics education was also proved difficult among medical students [30], among others. Dieticians are the primary and best qualified health care professionals for provision of nutrition therapy. As such, they particularly need to obtain further education and training in the field of nutrigenetics. Few studies evaluating the knowledge and perception of nutrigenetics among health care professionals in general and dieticians in particular have been reported. Our study findings indicate that dietitians would like to enhance their education and training in nutrigenetics.

PN should be perceived, understood, and utilized in a larger context, determining the individual's response to diet, which results from the interaction of metabolic, environmental, social, and genetic factors. Ultimately, with the evolution of high-throughput "omics" technologies, genetic information can be incorporated to predict individual risk factors of rare and common diseases, to incorporate knowledge regarding responders and nonresponders to specific nutritional patterns and to adjust general nutrition based on one's DNA. 
Another important consideration is consumer attitudes towards nutrigenetics. With dietitians being the first line of contact with the public regarding nutrigenetics inquiries (regardless of whether or not they are legally entitled to advise on these topics), it is necessary for dietitians to at least be familiar with the field of nutrigenetics. In fact, several studies focusing on this issue found positive attitudes towards nutrigenetics and its beneficial use, in parallel with concerns regarding confidentiality issues [31-34]. The importance of consumer attitudes and perception toward incorporation of nutrigenetics as part of nutritional therapy was demonstrated in the Food4Me study, where participants were genotyped and categorized as risk carriers (AA/AT) or nonrisk carriers (TT) of the fat-mass and obesity-associated (FTO) gene. Regardless of genotype, participants were randomized to one of four intervention groups: Dietary, phenotype, genotype, or control. Only participants in the genotype intervention group were informed of their FTO risk level. Compared to controls, participants with the FTO risk allele had greater reduction in measures of adiposity [35,36]. In contrast, knowledge of the MTHFR genotype (one of the factors associated with cardiovascular disease risk) was not associated with a change in dietary folate intake among Food4Me study participants [18].

The effects and magnitude of gene-nutrition interactions is being rapidly revealed. This information will eventually lead to reliable, scientifically sound individualized nutritional recommendations. Among the many remaining challenges are the need for strengthening the science, training professional personnel, as well as improving information delivery and public education. Thus, as the "genetic revolution" accelerates in a rapid pace, health professionals, including registered dieticians, are obligated to acquire sufficient and proper knowledge in genetics in order to fit to the new genetic paradigm. Despite this, the majority of health professionals surveyed in the present study expressed lack of knowledge in nutrigenetics but nevertheless indicated an eagerness to step into this field.

While at present the direct implications and applications of nutrigenetics in clinical dietetics are limited, commercial direct to consumer nutrigenetics information is already readily available, and clinical dietitians should be sufficiently knowledgeable in this field, even if to point out the extreme limitations of the clinical relevance of the information available at present. Moreover, the pace of acquired knowledge in the field is high and in coming years is expected to be of routine relevance to clinical dietetics, and thus knowledge and education in this field is of importance in preparing clinical dietitians for this new era.

Findings herein must be understood in the context of study limitations. First, the data are cross-sectional and, as such, causality cannot be inferred. Associations between sociodemographic or professional characteristics and level of knowledge are correlational only. Second, although this study tested knowledge objectively, it was limited to 12 questions and focused only on the theory of genetics and nutritional genomics and, as such, was not measured exhaustively. Finally, the study sample was drawn from registered attendees of a large nutrition conference. There is no way to determine the extent to which survey respondents are similar to or differ from the population of dietitians and other health care workers. This of course limits external validity. Nevertheless, the study population is large, which improves response prevalence estimates.

\section{Conclusions}

The field of nutrigenetics is developing rapidly in parallel to the huge advances in human genetics discoveries over the last decade, enabling major improvements in prevention, diagnosis, and treatment of many rare and common diseases. The enormous progress in biotechnology and bioinformatics enables economically-affordable sequencing of one's DNA and thus enables fast incorporation of genetic data into the clinical world. However, nutrigenetics is a complex field involving multiple factors and interactions, many of which are not yet well known or established. Thus, incorporation and implementation of nutrigenetics into practical dietetics should be critically examined and properly translated by nutrigenetics experts to the public. Similar to other health professions, the need for proper education in the field of human genetics was identified in the present study. Our findings clearly indicate that health professionals, and particularly dietitians, recognize the importance of 
acquiring knowledge in nutrigenetics. Only by acquiring the necessary scientific framework can dietitians accurately translate this knowledge into clinical practice and maintain their status as the nutrition expert.

Supplementary Materials: The following are available online at http://www.mdpi.com/2072-6643/12/2/335/s1. File S1: Knowledge attitudes and training survey of nutrigenetics.

Author Contributions: V.K.-S. and R.B. had primary responsibility for protocol development, questionnaire development, enrollment, outcome assessment, data analysis and interpretation, and writing the manuscript. H.S. and M.B. participated in the outcomes assessment and reviewed the final manuscript. All authors have read and agreed to the published version of the manuscript.

Funding: The organizing committee of the conference Unified forces, preventive nutrition contributed the prizes: A digital scale and professional literature.

Acknowledgments: We would like to thank the study participants. We also acknowledge the important contribution of Ruth Moshe for the assistance in data collection by the organizing committee of the conference Unified forces, preventive nutrition. May 2018, Israel.

Conflicts of Interest: The authors confirm that they have no conflicts to report.

\section{References}

1. Bordoni, L.; Gabbianelli, R. Primers on nutrigenetics and nutri(epi)genomics: Origins and development of precision nutrition. Biochimie 2019, 160, 156-171. [CrossRef] [PubMed]

2. Ramos-Lopez, O.; Milagro, F.I.; Allayee, H.; Chmurzynska, A.; Choi, M.S.; Curi, R.; De Caterina, R.; Ferguson, L.R.; Goni, L.; Kang, J.X.; et al. Guide for Current Nutrigenetic, nutrigenomic, and nutriepigenetic approaches for precision nutrition involving the prevention and management of chronic diseases associated with obesity. J Nutr. Nutr. 2017, 10, 43-62. [CrossRef] [PubMed]

3. Irimie, A.I.; Braicu, C.; Pasca, S.; Magdo, L.; Gulei, D.; Cojocneanu, R.; Ciocan, C.; Olariu, A.; Coza, O.; Berindan-Neagoe, I. Role of key micronutrients from nutrigenetic and nutrigenomic perspectives in cancer prevention. Medicina 2019, 55, 283. [CrossRef] [PubMed]

4. Kalia, S.S.; Adelman, K.; Bale, S.J.; Chung, W.K.; Eng, C.; Evans, J.P.; Herman, G.E.; Hufnagel, S.B.; Klein, T.E.; Korf, B.R.; et al. Recommendations for reporting of secondary findings in clinical exome and genome sequencing, 2016 update (ACMG SF v2.0): A policy statement of the American College of Medical Genetics and Genomics. Genet. Med. 2017, 19, 249-255. [CrossRef]

5. Aalfs, C.M.; Smets, E.M.; de Haes, H.C.; Leschot, N.J. Referral for genetic counselling during pregnancy: Limited alertness and awareness about genetic risk factors among GPs. Fam. Pract. 2003, 20, 135-141. [CrossRef]

6. Watson, E.K.; Shickle, D.; Qureshi, N.; Emery, J.; Austoker, J. The 'new genetics' and primary care: GPs' views on their role and their educational needs. Fam. Pract. 1999, 16, 420-425. [CrossRef]

7. Acton, R.T.; Burst, N.M.; Casebeer, L.; Ferguson, S.M.; Greene, P.; Laird, B.L.; Leviton, L. Knowledge, attitudes, and behaviors of Alabama's primary care physicians regarding cancer genetics. Acad. Med. 2000, 75, 850-852. [CrossRef]

8. Baars, M.J.; Henneman, L.; Ten Kate, L.P. Deficiency of knowledge of genetics and genetic tests among general practitioners, gynecologists, and pediatricians: A global problem. Genet. Med. 2005, 7, 605-610. [CrossRef]

9. Emery, J.; Watson, E.; Rose, P.; Andermann, A. A systematic review of the literature exploring the role of primary care in genetic services. Fam. Pract. 1999, 16, 426-445. [CrossRef]

10. Collins, J.; Bertrand, B.; Hayes, V.; Li, S.X.; Thomas, J.; Truby, H.; Whelan, K. The application of genetics and nutritional genomics in practice: An international survey of knowledge, involvement and confidence among dietitians in the US, Australia and the UK. Genes. Nutr. 2013, 8, 523-533. [CrossRef]

11. Camp, K.M.; Trujillo, E. Position of the academy of nutrition and dietetics: Nutritional genomics. J. Acad. Nutr. Diet. 2014, 114, 299-312. [CrossRef] [PubMed]

12. Misselwitz, B. Lactose intolerance: New insights due to blinded testing? Digestion 2014, 90, 72-73. [CrossRef] [PubMed]

13. Usai-Satta, P.; Scarpa, M.; Oppia, F.; Cabras, F. Lactose malabsorption and intolerance: What should be the best clinical management? World J. Gastrointest. Pharmacol. Ther. 2012, 3, 29-33. [CrossRef] [PubMed] 
14. Enattah, N.S.; Sahi, T.; Savilahti, E.; Terwilliger, J.D.; Peltonen, L.; Jarvela, I. Identification of a variant associated with adult-type hypolactasia. Nat. Genet. 2002, 30, 233-237. [CrossRef]

15. Lomer, M.C.; Parkes, G.C.; Sanderson, J.D. Review article: Lactose intolerance in clinical practice-myths and realities. Aliment. Pharmacol. Ther. 2008, 27, 93-103. [CrossRef]

16. Raz, M.; Sharon, Y.; Yerushalmi, B.; Birk, R. Frequency of LCT-13910C/T and LCT-22018G/A single nucleotide polymorphisms associated with adult-type hypolactasia/lactase persistence among Israelis of different ethnic groups. Gene 2013, 519, 67-70. [CrossRef]

17. Ponte, P.R.; de Medeiros, P.H.; Havt, A.; Caetano, J.A.; Cid, D.A.; Prata Mde, M.; Soares, A.M.; Guerrant, R.L.; Mychaleckyj, J.; Lima, A.A. Clinical evaluation, biochemistry and genetic polymorphism analysis for the diagnosis of lactose intolerance in a population from northeastern Brazil. Clinics 2016, 71, 82-89. [CrossRef]

18. O’Donovan, C.B.; Walsh, M.C.; Gibney, M.J.; Brennan, L.; Gibney, E.R. Knowing your genes: Does this impact behaviour change? Proc. Nutr. Soc. 2017, 76, 182-191. [CrossRef]

19. Celis-Morales, C.; Livingstone, K.M.; Marsaux, C.F.; Forster, H.; O’Donovan, C.B.; Woolhead, C.; Macready, A.L.; Fallaize, R.; Navas-Carretero, S.; San-Cristobal, R.; et al. Design and baseline characteristics of the Food4Me study: A web-based randomised controlled trial of personalised nutrition in seven European countries. Genes Nutr. 2015, 10, 014-0450. [CrossRef]

20. Macready, A.L.; Fallaize, R.; Butler, L.T.; Ellis, J.A.; Kuznesof, S.; Frewer, L.J.; Celis-Morales, C.; Livingstone, K.M.; Araujo-Soares, V.; Fischer, A.R.; et al. Application of behavior change techniques in a personalized nutrition electronic health intervention study: Protocol for the web-based Food4Me randomized controlled trial. JMIR Res. Protoc. 2018, 7, e87. [CrossRef]

21. Hollands, G.J.; French, D.P.; Griffin, S.J.; Prevost, A.T.; Sutton, S.; King, S.; Marteau, T.M. The impact of communicating genetic risks of disease on risk-reducing health behaviour: Systematic review with meta-analysis. Bmj 2016, 352, i1102. [CrossRef] [PubMed]

22. San-Cristobal, R.; Navas-Carretero, S.; Livingstone, K.M.; Celis-Morales, C.; Macready, A.L.; Fallaize, R.; O'Donovan, C.B.; Lambrinou, C.P.; Moschonis, G.; Marsaux, C.F.M.; et al. Mediterranean diet adherence and genetic background roles within a web-based nutritional intervention: The Food4Me Study. Nutrients 2017, 9, 1107. [CrossRef]

23. Rosen, R.; Earthman, C.; Marquart, L.; Reicks, M. Continuing education needs of registered dietitians regarding nutrigenomics. J. Am. Diet. Assoc. 2006, 106, 1242-1245. [CrossRef] [PubMed]

24. Whelan, K.; McCarthy, S.; Pufulete, M. Genetics and diet-gene interactions: Involvement, confidence and knowledge of dietitians. Br. J. Nutr. 2008, 99, 23-28. [CrossRef] [PubMed]

25. McCarthy, S.; Pufulete, M.; Whelan, K. Factors associated with knowledge of genetics and nutritional genomics among dietitians. J. Hum. Nutr. Diet. 2008, 21, 547-554. [CrossRef] [PubMed]

26. Prasad, C.; Imrhan, V.; Rew, M. Introducing nutritional genomics teaching in undergraduate dietetic curricula. J Nutr. Nutr. 2011, 4, 165-172. [CrossRef]

27. Van Langen, I.M.; Birnie, E.; Leschot, N.J.; Bonsel, G.J.; Wilde, A.A. Genetic knowledge and counselling skills of Dutch cardiologists: Sufficient for the genomics era? Eur. Heart J. 2003, 24, 560-566. [CrossRef]

28. Carroll, J.C.; Rideout, A.L.; Wilson, B.J.; Allanson, J.M.; Blaine, S.M.; Esplen, M.J.; Farrell, S.A.; Graham, G.E.; MacKenzie, J.; Meschino, W.; et al. Genetic education for primary care providers: Improving attitudes, knowledge, and confidence. Can. Fam. Physician. 2009, 55, e92-e99.

29. Kanny, E.M.; Smith, R.; Dudgeon, B.J. Genetics in occupational therapy education: A survey of professional entry-level programs. Am. J. Occup. Ther. 2005, 59, 165-172. [CrossRef]

30. Metcalf, M.P.; Tanner, T.B.; Buchanan, A. Effectiveness of an online curriculum for medical students on genetics, genetic testing and counseling. Med. Educ. Online 2010, 15. [CrossRef]

31. Vallee Marcotte, B.; Cormier, H.; Garneau, V.; Robitaille, J.; Desroches, S.; Vohl, M.C. Nutrigenetic testing for personalized nutrition: An evaluation of public perceptions, attitudes, and concerns in a population of French Canadians. Lifestyle Genom. 2018, 11, 155-162. [CrossRef] [PubMed]

32. Vallee Marcotte, B.; Cormier, H.; Garneau, V.; Robitaille, J.; Desroches, S.; Vohl, M.C. Current knowledge and interest of French Canadians regarding nutrigenetics. Genes Nutr. 2019, 14, 019-0629. [CrossRef] [PubMed]

33. Nielsen, D.E.; Shih, S.; El-Sohemy, A. Perceptions of genetic testing for personalized nutrition: A randomized trial of DNA-based dietary advice. J. Nutr. Nutr. 2014, 7, 94-104. [CrossRef] [PubMed] 
34. Berezowska, A.; Fischer, A.R.; Ronteltap, A.; Kuznesof, S.; Macready, A.; Fallaize, R.; van Trijp, H.C. Understanding consumer evaluations of personalised nutrition services in terms of the privacy calculus: A qualitative study. Public Health Genom. 2014, 17, 127-140. [CrossRef] [PubMed]

35. Celis-Morales, C.; Marsaux, C.F.; Livingstone, K.M.; Navas-Carretero, S.; San-Cristobal, R.; Fallaize, R.; Macready, A.L.; O'Donovan, C.; Woolhead, C.; Forster, H.; et al. Can genetic-based advice help you lose weight? Findings from the Food4Me European randomized controlled trial. Am. J. Clin. Nutr. 2017, 105, 1204-1213. [CrossRef] [PubMed]

36. Celis-Morales, C.; Lara, J.; Mathers, J.C. Personalising nutritional guidance for more effective behaviour change. Proc. Nutr. Soc. 2015, 74, 130-138. [CrossRef] [PubMed]

(C) 2020 by the authors. Licensee MDPI, Basel, Switzerland. This article is an open access article distributed under the terms and conditions of the Creative Commons Attribution (CC BY) license (http://creativecommons.org/licenses/by/4.0/). 